ARTICLE

DOI: $10.1038 / s 41467-017-01694-y$

\title{
Redox-independent chromium isotope fractionation induced by ligand-promoted dissolution
}

Emily M. Saad ${ }^{1}$, Xiangli Wang ${ }^{2}$, Noah J. Planavsky² ${ }^{2}$ Christopher T. Reinhard ${ }^{1} \&$ Yuanzhi Tang ${ }^{1}$

The chromium ( $\mathrm{Cr}$ ) isotope system has emerged as a potential proxy for tracing the Earth's atmospheric evolution based on a redox-dependent framework for $\mathrm{Cr}$ mobilization and isotope fractionation. Although studies have demonstrated that redox-independent pathways can also mobilize $\mathrm{Cr}$, no quantitative constraints exist on the associated isotope fractionations. Here we survey the effects of common environmental ligands on the dissolution of $\mathrm{Cr}$ (III)-(oxy)hydroxide solids and associated $\mathrm{Cr}$ isotope fractionation. For a variety of organic acids and siderophores, $\delta^{53} \mathrm{Cr}$ values of dissolved $\mathrm{Cr}$ (III) are -0.27 to $1.23 \%$, within the range of previously observed $\mathrm{Cr}$ isotope signatures in rock records linked to $\mathrm{Cr}$ redox cycling. Thus, ligand-promoted dissolution of $\mathrm{Cr}$-containing solids, a redox-independent process, must be taken into account when using sedimentary $\mathrm{Cr}$ isotope signatures to diagnose atmospheric oxygen levels. This work provides a step towards establishing a more robust framework for using $\mathrm{Cr}$ isotopes to track the evolution of the Earth's atmosphere.

\footnotetext{
${ }^{1}$ School of Earth and Atmospheric Sciences, Georgia Institute of Technology, Atlanta, GA 30332, USA. ${ }^{2}$ Department of Geology and Geophysics, Yale University, New Haven, CT 06511, USA. Correspondence and requests for materials should be addressed to Y.T. (email: yuanzhi.tang@eas.gatech.edu)
} 
$\mathrm{T}$ he chromium (Cr) isotope system has been exploited as a highly discriminating tracer of redox processes in the Earth's surface environments, and is under development as a novel paleobarometer for atmospheric oxygen levels ${ }^{1-5}$. Many of these applications are based on the assumption that $\mathrm{Cr}$ isotope fractionations are linked predominantly to $\mathrm{Cr}$ redox transformations. Consistent with this view, theoretical and experimental studies have suggested very little $\mathrm{Cr}$ fractionation during redoxindependent processes, such as adsorption ${ }^{6}$, though recent experimental studies demonstrated large equilibrium fractionations between various $\mathrm{Cr}-\mathrm{Cl}$ species $^{7}$. $\mathrm{Cr}$ isotopes have been extensively employed in environmental geochemistry as a quantitative proxy for $\mathrm{Cr}$ transport and remediation efficiency (see ref. ${ }^{8}$ and references therein). However, in order to quantitatively apply this isotope system as a tracer for Earth's surface processes, it is critical to more precisely quantify a wider range of factors controlling the global $\mathrm{Cr}$ cycle and isotope budget ${ }^{9}$. Indeed, since the early proposed uses of the $\mathrm{Cr}$ isotope system, there have been several studies recognizing the need to account for other biogeochemical processes in addition to the redox pathway-based framework of this isotope system ${ }^{7,10-14}$.

The two most common oxidation states of $\mathrm{Cr}$ in natural environments are $\mathrm{Cr}(\mathrm{III})$ and $\mathrm{Cr}(\mathrm{VI})$. $\mathrm{Cr}(\mathrm{III})$ is typically insoluble and is the most common form of $\mathrm{Cr}$ in rocks and minerals at the Earth's surface. $\mathrm{Cr}(\mathrm{VI})$ is typically soluble and is the dominant form of mobile $\mathrm{Cr}$ in natural environments. The standard view of the $\mathrm{Cr}$ isotope paleoredox proxy is grounded in the idea that oxidative weathering of $\mathrm{Cr}$ (III)-containing minerals by manganese (Mn) oxides, the formation of which requires free oxygen, is required for $\mathrm{Cr}$ redox cycling and $\mathrm{Cr}$ isotope fractionations. During this oxidation process, soluble $\mathrm{Cr}(\mathrm{VI})$ is released and transported to oceans, reduced to $\mathrm{Cr}(\mathrm{III})$ under reducing environments, and deposited in marine sediments ${ }^{1,15}$. Thus, authigenic marine sediments capture an integrated isotopic signature reflective of the redox processes involved in $\mathrm{Cr}(\mathrm{III})$ oxidative mobilization, downstream $\mathrm{Cr}(\mathrm{VI})$ reduction, and ultimate $\mathrm{Cr}(\mathrm{III})$ burial in sediments ${ }^{1}$.

The redox transformation between $\mathrm{Cr}(\mathrm{III})$ and $\mathrm{Cr}(\mathrm{VI})$ causes a significant change in the local coordination environment of $\mathrm{Cr}$. Cr (III) typically occurs as an octahedrally coordinated cation, whereas $\mathrm{Cr}(\mathrm{VI})$ primarily occurs as a tetrahedrally coordinated oxyanion. The large change in coordination environment during redox transformations leads to significant isotopic fractionation, similar to other redox-sensitive elements ${ }^{16}$. Unweathered igneous rocks, with limited exceptions ${ }^{17}$, exhibit a narrow range of ${ }^{53} \mathrm{Cr}$ values of $-0.124 \pm 0.101 \%$ o (defined as $\delta^{53} \mathrm{Cr}=\left[{ }^{53} \mathrm{Cr} /{ }^{52} \mathrm{Cr}\right.$ ) sample $/$ $\left.\left.\left({ }^{53} \mathrm{Cr} /{ }^{52} \mathrm{Cr}\right)_{\text {standard }}-1\right] \times 1000\right)^{15}$. $\mathrm{Cr}(\mathrm{III})$ oxidation to $\mathrm{Cr}(\mathrm{VI})$ can result in significant isotopic fractionations, both negative and positive $\left({ }^{53} \varepsilon_{\mathrm{Cr}(\mathrm{VI})-\mathrm{Cr}(\mathrm{III})}\right.$ ranging from -2.5 to $+1.1 \%$ o), depending on the reaction conditions; while reduction of $\mathrm{Cr}(\mathrm{VI})$ to $\mathrm{Cr}(\mathrm{III})$ has consistently been shown to leave the remaining $\mathrm{Cr}(\mathrm{VI})$ isotopically heavy $\left({ }^{53} \varepsilon_{\mathrm{Cr}(\mathrm{III})-\mathrm{Cr}(\mathrm{VI})}\right.$ ranging from -7.6 to $-0.4 \%$ ) (see, e.g., ref. $^{8}$ ). Because the isotopic exchange and subsequent isotopic equilibrium between $\mathrm{Cr}(\mathrm{III})$ and $\mathrm{Cr}(\mathrm{VI})$ requires three electron transfer with a significant coordination reconfiguration, the isotopic exchange rate of these species is extremely slow ${ }^{18,19}$. However, when dissolved $\mathrm{Cr}(\mathrm{VI})$ - and $\mathrm{Cr}(\mathrm{III})$-containing solids are in contact for long periods, equilibrium fractionation may become relevant. The significance of such a process under actual environmental settings (e.g., during the weathering of $\mathrm{Cr}$-containing rocks/minerals) can vary and is dependent on many factors, such as the relative ratio of the exchanging $\mathrm{Cr}(\mathrm{VI})$ and $\mathrm{Cr}(\mathrm{III})$ species $^{19}$. Therefore, $\mathrm{Cr}$ isotope systematics during the Earth's surface processes are generally assumed to be dominated by kinetic fractionations. Regardless, current experimental and empirical results suggest that both kinetic and equilibrium processes tend to lead to $\mathrm{Cr}(\mathrm{VI})$ that is isotopically heavy ${ }^{19,20}$.
One generally overlooked mechanism for $\mathrm{Cr}$ (III) mobilization is ligand complexation. Indeed, measurements on natural waters have revealed elevated concentrations of dissolved $\mathrm{Cr}$ (III) that are higher than the solubility of $\mathrm{Cr}(\mathrm{OH})_{3}$ solids, one common sink phase of $\mathrm{Cr}(\mathrm{III})$, and suggest the likely complexation of $\mathrm{Cr}$ (III) by inorganic $^{21}$ and/or organic molecules (e.g., refs. ${ }^{22-24}$ ). The speciation of $\mathrm{Cr}$ in hydrothermal fluids, and marine settings more broadly, is also thought to be influenced by organically complexed $\mathrm{Cr}(\mathrm{III})^{25,26}$. Two classes of organic ligands, siderophores (e.g., desferrioxamine $\mathrm{B}$, rhizoferrin, protochelin $)^{27}$ and organic acids (e.g., citric acid, ethylenediaminetetraacetic acid, nitrilotriacetic acid $^{28}$, have been shown to be capable of solubilizing $\mathrm{Cr}$ (III) from the $\mathrm{Cr}(\mathrm{OH})_{3}$ solid phase under environmentally relevant conditions. Both siderophores and organic acids are ubiquitous organic molecules in natural environments and are produced by a wide range of microorganisms and often co-exuded ${ }^{29}$. Siderophores are organic chelating agents with a high affinity for $\mathrm{Fe}(\mathrm{III})$ for enhancing $\mathrm{Fe}$ dissolution from low-solubility $\mathrm{Fe}(\mathrm{III})$-mineral phases $^{30}$. Siderophores have also been shown to have strong affinities for other trivalent metal cations such as $\mathrm{Cr}$ (III) due to their structural similarity (e.g., size, coordination environment) to $\mathrm{Fe}(\mathrm{III})^{31}$. Organic acids are known to contribute to the mobilization of metals in soils 32 , and a wide range of organic acids (e.g., oxalic, citric, fulvic, and humic acids) have been shown to complex with $\mathrm{Cr}(\mathrm{III})^{33-35}$. Organic acids are likely to have been present throughout the Earth's history through abiotic or biotic synthesis pathways (see, e.g., refs. ${ }^{36,37}$ ) and may have played important roles in the weathering ${ }^{38}$ of poorly soluble transition metals.

Despite the potential importance of $\mathrm{Cr}(\mathrm{III})$-ligand complexes in Earth's surface, $\mathrm{Cr}$ isotope fractionation during $\mathrm{Cr}(\mathrm{III}) \mathrm{com}$ plexation with organic ligands has not been experimentally measured, although the potential for fractionation upon complexation with inorganic ligands has been previously suggested by theoretical studies ${ }^{19,20}$ and observed experimentally ${ }^{7}$. Additionally, several recent studies have inferred redox-independent $\mathrm{Cr}$ cycling in the interpretation of relevant rock records based on the site-specific geochemistry and $\mathrm{Cr}$ isotope dynamics ${ }^{10,11}$.

Here, we survey the extent of $\mathrm{Cr}$ isotope fractionation that occurs during ligand complexation and dissolution of $\mathrm{Cr}(\mathrm{III})$ containing solid phases. Given the potential for analytically significant fractionations, these redox-independent processes may add complexity when using $\mathrm{Cr}$ isotopes to track $\mathrm{Cr}$ oxidative mobilization and $\mathrm{Cr}$ reduction during environmental remediation. We systematically characterize the dissolution of a $\operatorname{Cr}(\mathrm{III})$ containing solid by a wide range of organic ligands, and quantified the attendant isotope effects with an eye toward better understanding the potential impact of $\mathrm{Cr}$ (III)-ligand complexation on global $\mathrm{Cr}$ cycling and interpretation of isotope signatures.

\section{Results}

Ligand promoted dissolution. In the absence of organic ligands, dissolved $\mathrm{Cr}$ remained $<0.5 \mu \mathrm{M}$ throughout the experiment with detectable release only occurring after 14 days (Fig. 1a). The presence of organic ligands promoted the dissolution of $\mathrm{Cr}$ to variable extents (Fig. 1). In the presence of organic acids alone, citrate released the greatest amount of $\mathrm{Cr}$, reaching a plateau at $3.5 \mu \mathrm{M}$, followed by oxalate, which reached $2.4 \mu \mathrm{M}$ by the end of the experiment (Fig. 1a). The presence of a dissolution plateau is possibly due to surface passivation. Succinate and acetate promoted $\mathrm{Cr}$ release to a similar extent as the control (i.e., no organic ligands), reaching 0.5 and $0.4 \mu \mathrm{M}$, respectively, at the end of experiments, both with detectable $\mathrm{Cr}$ throughout the experiment (whereas in control experiments dissolved $\mathrm{Cr}$ was only detected after $\sim 15$ days). The presence of both desferrioxamine B (DFOB) and organic acids resulted in similar dissolution trends as the 

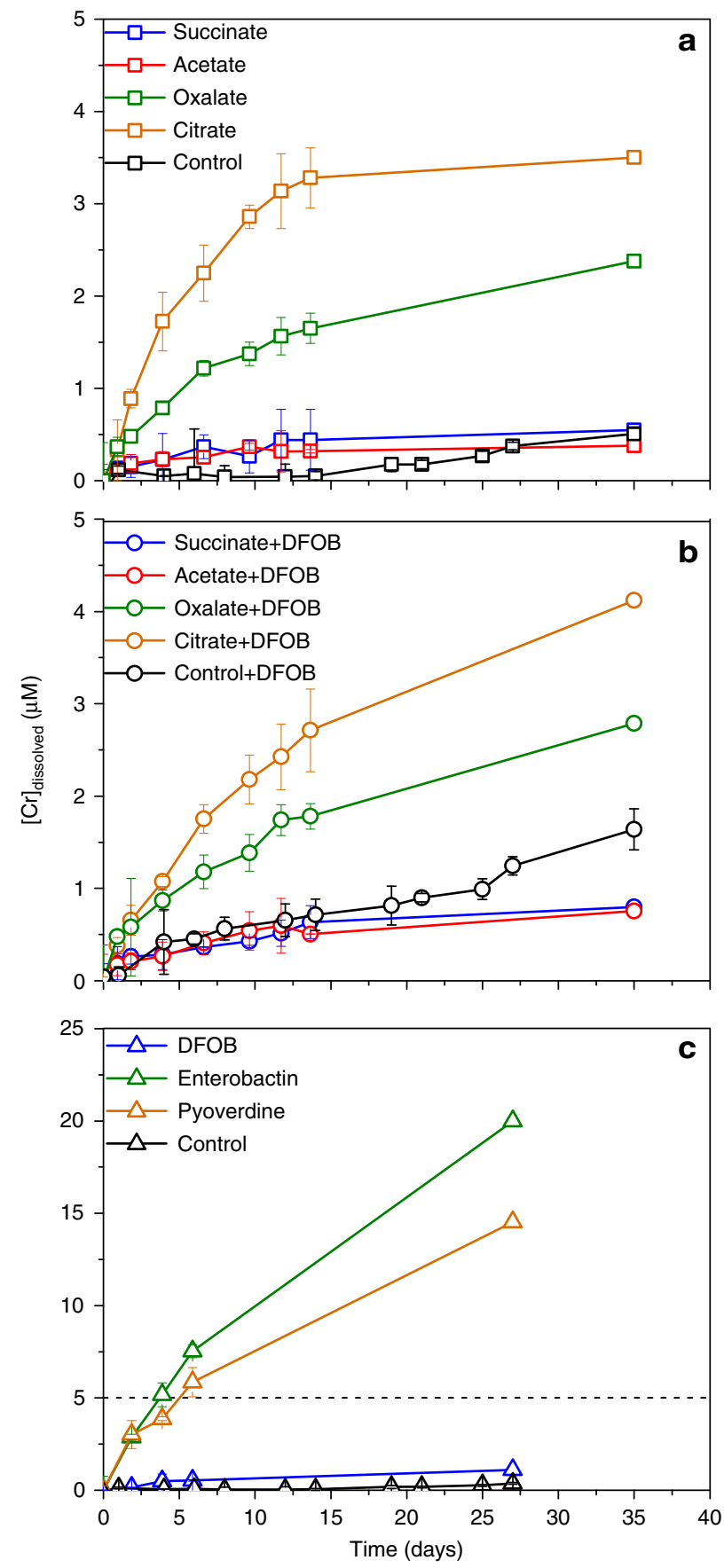

Fig. $1 \mathrm{Cr}$ dissolution profile in the presence of different ligands. Dissolved $\mathrm{Cr}$ concentrations in the presence of $\mathbf{a}$ organic acids only, $\mathbf{b}$ organic acids and the siderophore, desferrioxamine $B$ (DFOB), and $\mathbf{c}$ siderophores only. Experimental conditions are $0.2 \mathrm{gl}^{-1}$ of $\mathrm{Cr}(\mathrm{OH})_{3}$ at $\mathrm{pH} 7$ (10 mM HEPES), and ionic strength of $0.1 \mathrm{M}$. Error bars represent the standard deviation between replicates. The dashed line in (c) indicates the maximum value of the $y$-axis in (a) and (b). All dissolved $\mathrm{Cr}$ was determined to be in the +3 oxidation state

organic acid-only treatments (Fig. 1b). Citrate, followed by oxalate, induced the greatest amount of dissolved $\mathrm{Cr}$, reaching 4.1 and $2.7 \mu \mathrm{M}$, respectively, and with continuous increase at the end of the experiment. The addition of succinate and acetate with DFOB both resulted in an $\sim 0.8 \mu \mathrm{M}$ dissolved $\mathrm{Cr}$ at the end of the experiment, less than in the presence of DFOB alone $(1.5 \mu \mathrm{M})$. $\mathrm{Cr}$ dissolution was also dependent on siderophore type (Fig. 1c). Enterobactin resulted in the greatest amount of dissolved $\mathrm{Cr}(20$
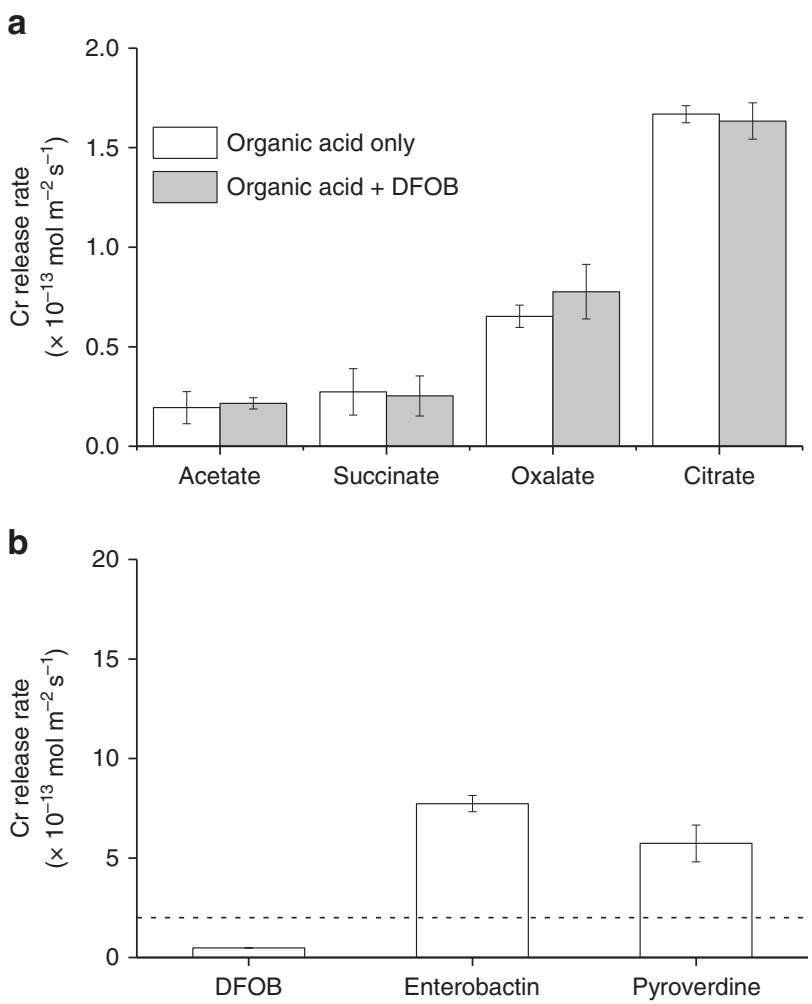

Fig. $2 \mathrm{Cr}$ dissolution rate in the presence of different ligands. The initial surface area normalized release rates of $\mathrm{Cr}$ from $\mathrm{Cr}(\mathrm{OH})_{3}$ in the presence of a organic acids with and without the siderophore, desferrioxamine $B$ (DFOB), or $\mathbf{b}$ siderophores only. The dashed line in (b) is at the maximum $y$-value of (a). The average rates of replicates are presented with error bars reflecting standard deviation between replicates. Experimental conditions are $0.2 \mathrm{gl}^{-1}$ of $\mathrm{Cr}(\mathrm{OH})_{3}$ at $\mathrm{pH} 7(10 \mathrm{mM} \mathrm{HEPES})$ and ionic strength of $0.1 \mathrm{M}$

$\mu \mathrm{M})$, followed by pyoverdine $(15 \mu \mathrm{M})$ and DFOB $(1.5 \mu \mathrm{M})$. None of the siderophore-only treatments reached a concentration plateau by the end of the experiment.

Both siderophores and organic acids increased the initial $\mathrm{Cr}$ release rates (surface area normalized) relative to the absence of a ligand, for which an initial dissolution rate could not be calculated by linear regression $\left(R^{2}=0.2\right)$ (Fig. 2 and Supplementary Table 1). In the presence of organic acids, initial Cr release rates were highest for citrate $\left(1.6 \pm 0.1 \times 10^{-13} \mathrm{~mol} \mathrm{~m}^{-2} \mathrm{~s}^{-1}\right)$, followed by oxalate $\left(6.5 \pm 0.6 \times 10^{-14} \mathrm{~mol} \mathrm{~m}^{-2} \mathrm{~s}^{-1}\right)$, and succinate and acetate (both $\sim 2 \times 10^{-14} \mathrm{~mol} \mathrm{~m}^{-} \mathrm{s}^{-1}$ ) (Fig. 2a and Supplementary Table 1). The combined presence of DFOB and organic acids did not significantly affect the dissolution rate relative to experiments with organic acids alone. In the presence of siderophores alone, initial $\mathrm{Cr}$ release rates were highest for enterobactin $\left(7.7 \pm 0.4 \times 10^{-13} \mathrm{~mol} \mathrm{~m}^{-2} \mathrm{~s}^{-1}\right)$, followed by pyoverdine $\left(5.7 \pm 0.9 \times 10^{-13} \mathrm{~mol} \mathrm{~m}^{-2} \mathrm{~s}^{-1}\right)$, and finally DFOB $(4.8 \pm$ $0.1 \times 10^{-14} \mathrm{~mol} \mathrm{~m}^{-2} \mathrm{~s}^{-1}$ ) (Fig. $2 \mathrm{~b}$ and Supplementary Table 1 ). In general, organic acids released less $\mathrm{Cr}$ into solution than siderophores. The exception is citrate, which resulted in a dissolution rate around 3 times greater than that of DFOB.

Cr isotopic composition. The $\mathrm{Cr}$ isotopic composition of the dissolved $\mathrm{Cr}$ (III) was also examined throughout the experiments (Fig. 3). A wide range of $\delta^{53} \mathrm{Cr}$ values were observed in the solubilized $\mathrm{Cr}$, from +1.23 to $-0.27 \%$. The $\delta^{53} \mathrm{Cr}$ values varied based on ligand type and reaction extent. The isotope signature of dissolved $\mathrm{Cr}$ approaches that of the original solid with increasing reaction extent for the experiments with organic acids only. 


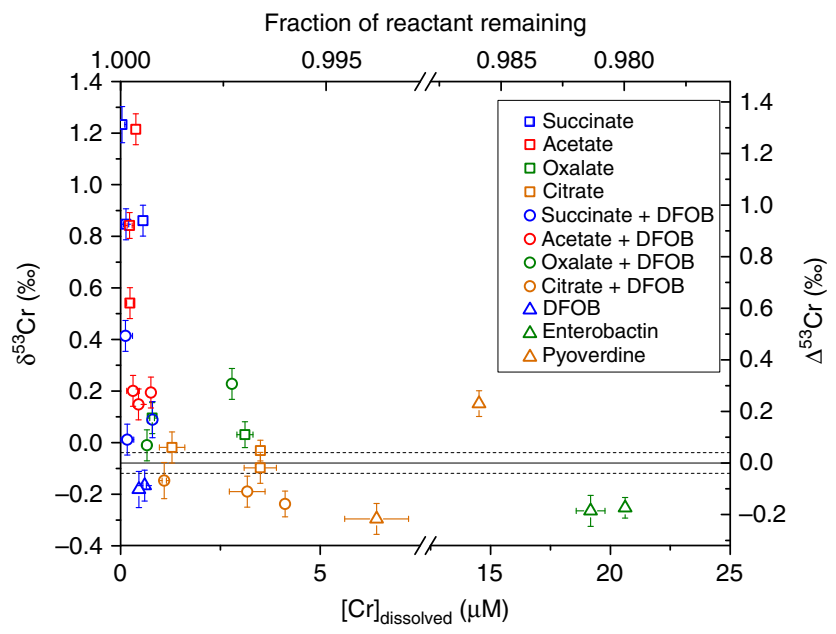

Fig. $3 \mathrm{Cr}$ isotope composition. $\delta^{53} \mathrm{Cr}$ as a function of reaction extent (either fraction of reactant remaining or concentration of $\mathrm{Cr}$ dissolved) for each ligand or ligand combination. $\Delta^{53} \mathrm{Cr}$ represents $\delta^{53} \mathrm{Cr}_{\text {solution }}-\delta^{53} \mathrm{Cr}_{\text {initial solid }}$ at distinct points during dissolution. The isotopic signature of the starting solid is represented by the solid line at $\delta^{53} \mathrm{Cr}=-0.08 \%$ and $\Delta^{53} \mathrm{Cr}=0$. The dashed lines represent $\pm 2 \sigma$ (analytical measurement reproducibility). Experimental conditions are $0.2 \mathrm{gl}^{-1}$ of $\mathrm{Cr}(\mathrm{OH})_{3}$ at $\mathrm{pH} 7$ (10 mM HEPES) and ionic strength of $0.1 \mathrm{M}$

Interestingly, though the influence of DFOB on organic acidpromoted dissolution was not obvious with regard to $\mathrm{Cr}$ (III) release rates, a significant impact on the magnitude of isotopic fractionation was observed when comparing DFOB+organic acid experiments to organic acid-only experiments.

\section{Discussion}

Organic ligands are known to promote the dissolution of metal oxides by forming inner sphere metal-ligand complexes at the solid-solution interface and weakening the metal-oxygen bond on the solid surface. The structure of the ligand influences the stability of both the surface and dissolved metal-ligand complexes and consequently the rate of dissolution. The rate-limiting step during ligand-promoted dissolution is the detachment of the metal-ligand complex from the surface; thus, increasing stability of the dissolved metal-ligand complex leads to increasing dissolution rate ${ }^{39}$. The stability constants of $\mathrm{Cr}$ (III)-siderophore complexes are not well established due to the slow ligand exchange rate, weak ultraviolet-visible (UV-vis) absorbances, and low reduction potentials, all of which prevent traditional methods for the determination of stability constants (see ref. ${ }^{27}$ and references therein). Because limited stability data are available for $\mathrm{Cr}(\mathrm{III})$-ligand complexes for the ligands studied here, the following discussions will use the stability constants of $\mathrm{Fe}$ (III)-ligand complexes to estimate the potential influences of such factor on dissolution and isotope fractionation. The rationale for using $\mathrm{Fe}$ (III)-ligand complex stability constants as proxies is based on the similar strength of interaction between $\mathrm{Fe}$ (III) or $\mathrm{Cr}$ (III) cations and a ligand containing a hard Lewis base (i.e., the hardness of the cation is similar) ${ }^{40}$. Therefore, the ionic potential of metal cations (i.e., valence divided by ionic radius) positively correlates with the metal-ligand stability constant ${ }^{27,40}$. The similarity of the ionic potential of $\mathrm{Fe}$ (III) (ionic radius of $0.645 \AA$ ) to $\operatorname{Cr}(\mathrm{III})$ (ionic radius of $0.615 \AA)^{41}$ allows for an appropriate first estimation of $\mathrm{Cr}(\mathrm{III})$-ligand trends. Although a more complete estimation of the $\mathrm{Cr}$ (III)-ligand stability constants would require the metal-ligand stability constants for a greater number of metals ${ }^{27,40}$, we suggest using Fe(III) stability constants as a first-order approximation of the corresponding $\mathrm{Cr}$

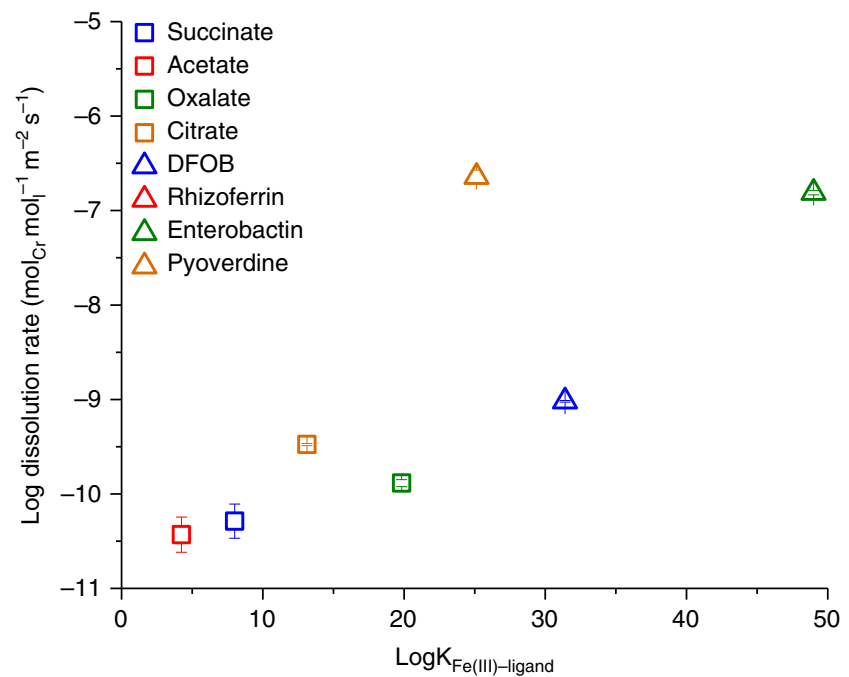

Fig. $4 \mathrm{Cr}$ dissolution rate vs metal-ligand stability constants. Initial dissolution rates of $0.2 \mathrm{~g} \mathrm{I}^{-1}$ of $\mathrm{Cr}(\mathrm{OH})_{3}\left(\mathrm{~mol} \mathrm{Cr}\right.$ mol ligand ${ }^{-1} \mathrm{~m}^{-2} \mathrm{~s}^{-1}$ ) at $\mathrm{pH} 7$ and ionic strength of $0.1 \mathrm{M}$ as a function of the stability constant of the corresponding Fe(III)-ligand complexes. Stability constants are for Fe (III)-organic acid complexes ${ }^{44}$ predicted to be the most thermodynamically stable under these conditions using MINTEQ ${ }^{43}$. Fe(III)-siderophore stability constants are for the $\mathrm{Fe}(\mathrm{III})$-siderophore complex with a completely unprotonated ligand (see ref. 45 and references therein). Fe(III)-ligand stability constants are presented for consistency due to the similarity in ionic potential between $\mathrm{Fe}(\mathrm{III})$ and $\mathrm{Cr}(\mathrm{III})$, because $\mathrm{Cr}(\mathrm{III})$-ligand stability constants are not available for all ligands

(III)-ligand complex stabilities. However, it should be noted that in some instances the measured values of $\mathrm{Cr}$ (III)-ligand stability, specifically for siderophores, do not necessarily follow the correlating Fe(III)-ligand stability trends, as has been observed for rhizoferrin, an $\alpha$-hydroxycarboxylate-type siderophore, where the Cr(III)-rhizoferrin stability constant is 4 orders of magnitude higher than for the corresponding Fe(III)-rhizoferrin complex ${ }^{27}$. The difference in siderophore affinity has also been previously noted between $\mathrm{Fe}$ (III) and $\mathrm{Mn}$ (III) due to the identity of the binding moiety of the siderophore and the electron configuration of the metal atoms ${ }^{42}$.

In the presence of organic acids, we find that dissolution rates generally increase with increasing stability constant of the corresponding $\mathrm{Fe}$ (III)-ligand complex (Fig. 4 and Supplementary Fig. 1$)^{43-45}$. Of the organic acids utilized here, citrate, a strong chelating ligand, exhibited the greatest dissolution rate at $0.27 \pm$ $0.01 \mu \mathrm{M} \mathrm{d}^{-1}\left(1.67 \pm 0.04 \times 10^{-13} \mathrm{~mol} \mathrm{~m}^{-2} \mathrm{~s}^{-1}\right.$; change in units in order to offer a consistent comparison), consistent with the previously reported rate of citrate-promoted $\mathrm{Cr}(\mathrm{OH})_{3}$ dissolution under similar experimental conditions $\left(0.22 \pm 0.09 \mu \mathrm{M} \mathrm{d}^{-1}\right)^{28}$. Although the rates of organic acid-promoted dissolution of $\mathrm{Cr}$ $(\mathrm{OH})_{3}$ for oxalate, succinate, and acetate have not been reported to our knowledge, inference can be made based on the trends observed with Fe oxides. For example, similar trends of dissolution rates have been observed for organic acid-promoted ferrihydrite dissolution at $\mathrm{pH} 7$, which decreased in the order of citrate, oxalate, and succinate ${ }^{46}$. These trends can be described by the binding mechanism exhibited by each ligand. Citrate has been shown to adsorb to $\mathrm{Fe}$ oxides with each carboxyl group bound to different $\mathrm{Fe}(\mathrm{III})$ sites on the solid surface, leading to its effectiveness at dissolving metal oxides ${ }^{47}$. Oxalate has been shown to form a bidentate mononuclear complex with $\mathrm{Fe}$ (III) in hematite, while succinate formed a (weaker) monodentate surface complex, leading to the observed differences in dissolution rates ${ }^{48}$. Acetate 


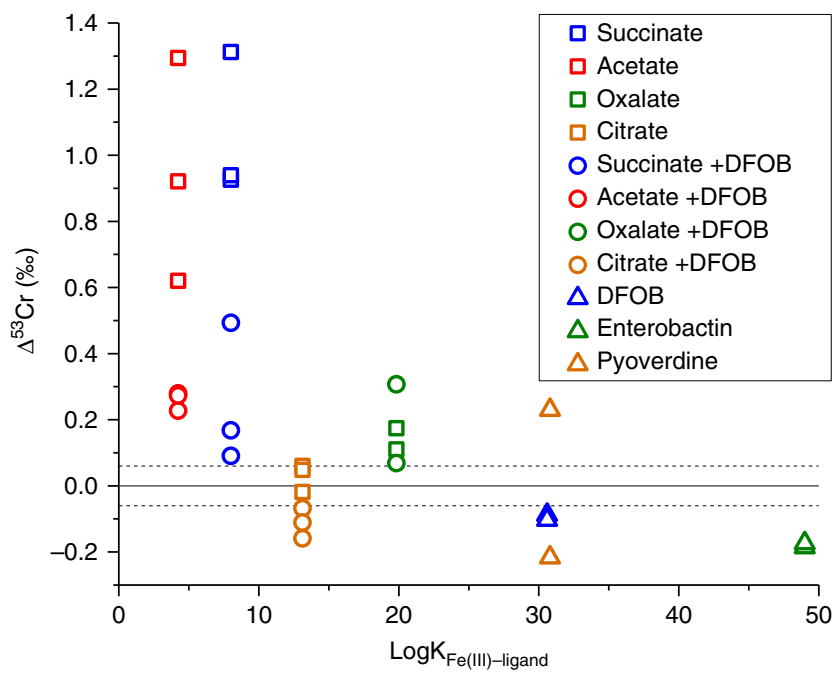

Fig. $5 \mathrm{Cr}$ isotope fractionation vs metal-ligand stability constant. $\Delta^{53} \mathrm{Cr}$ (defined as $\Delta^{53} \mathrm{Cr}=\delta^{53} \mathrm{Cr}_{\text {solution }}-\delta^{53} \mathrm{Cr}_{\text {starting solid) at } \mathrm{pH} 7 \text { and ionic }}$ strength of $0.1 \mathrm{M}$ as a function of the stability constant of the corresponding $\mathrm{Fe}$ (III)-ligand complex. The data points for each condition represent complete harvests at various times throughout the experiment. Stability constants are for Fe(III)-organic acid complexes ${ }^{44}$ predicted to be the most thermodynamically stable under these conditions using MINTEQ $^{43}$. Fe (III)-siderophore stability constants are for the Fe(III)-siderophore complex with a completely unprotonated ligand (see ref. ${ }^{45}$ and references therein). This plot is presented with the caveat that not all dissolved metal may be ligand complexed. Fe(III)-ligand stability constants are presented for consistency as $\mathrm{Cr}(\mathrm{III})$-ligand stability constants are not available for all ligands and due to the similarity in ionic potential between $\mathrm{Fe}(\mathrm{III})$ and $\mathrm{Cr}$ (III). No observed isotopic fractionation is indicated by the solid line at $\Delta^{53} \mathrm{Cr}=0$. The dashed lines represent $\pm 2 \sigma$

is a monodentate ligand that has been shown to preferentially occupy adsorption sites on metal oxide surfaces ${ }^{28}$, though is not expected to significantly affect the dissolution rate ${ }^{49}$. In general, the trends in organic acid-promoted dissolution observed in this study are consistent with expectations.

The dissolution of $\mathrm{Cr}(\mathrm{OH})_{3}$ by siderophores has recently been studied at several $\mathrm{pH}$ values by Duckworth et al. ${ }^{27}$. The average surface area normalized dissolution rates at $\mathrm{pH} 7$ and under similar experimental conditions $\left(0.2 \mathrm{gl}^{-1} \mathrm{Cr}(\mathrm{OH})_{3}, 100 \mu \mathrm{M}\right.$ siderophore, $10 \mathrm{mM}$ 4-(2-hydroxyethyl)-1-piperazineethanesulfonic acid (HEPES)) were $4.3 \pm 0.7 \times 10^{-13} \mathrm{~mol} \mathrm{~m}^{-2} \mathrm{~s}^{-1}$ for DFOB and $3.0 \pm 1.7 \times 10^{-12} \mathrm{~mol} \mathrm{~m}^{-2} \mathrm{~s}^{-1}$ for protochelin (a triscatecholatetype siderophore like enterobactin) ${ }^{27}$, both of which are within a factor of 10 of rates observed in this experiment (Fig. 2 and Supplementary Table 1). The differences in observed rates may be the result of differences in properties of the initial synthesized $\mathrm{Cr}(\mathrm{OH})_{3}$ solids (i.e., aggregation) and the difference in the number of time points considered. Unlike organic acids, the relationship between stability constant and dissolution rate of the siderophores does not appear to be correlated (Fig. 4 and Supplementary Fig. 1$)^{43-45}$, similar to what was observed in Duckworth et al. ${ }^{27}$. However, as mentioned previously, siderophore observations with $\mathrm{Cr}$ may not be explicitly comparable to the $\mathrm{Fe}$ (III)-siderophore stability constants. For the ligands with an available Cr-ligand stability constant and dominant species at the experimental conditions, Cr-acetate $(\operatorname{logK}=15)^{43,44}$ and Cr-DFOB $(\operatorname{logK}=33)^{27}$, general agreement between the Cr-ligand and Fe-ligand stability constant correlation with stability constant is observed. While Fe oxide dissolution rates have been shown to positively correlate to the $\mathrm{Fe}(\mathrm{III})$-ligand stability constant ${ }^{50}$, $\mathrm{Cr}(\mathrm{III})$-siderophore complexes have been shown to behave

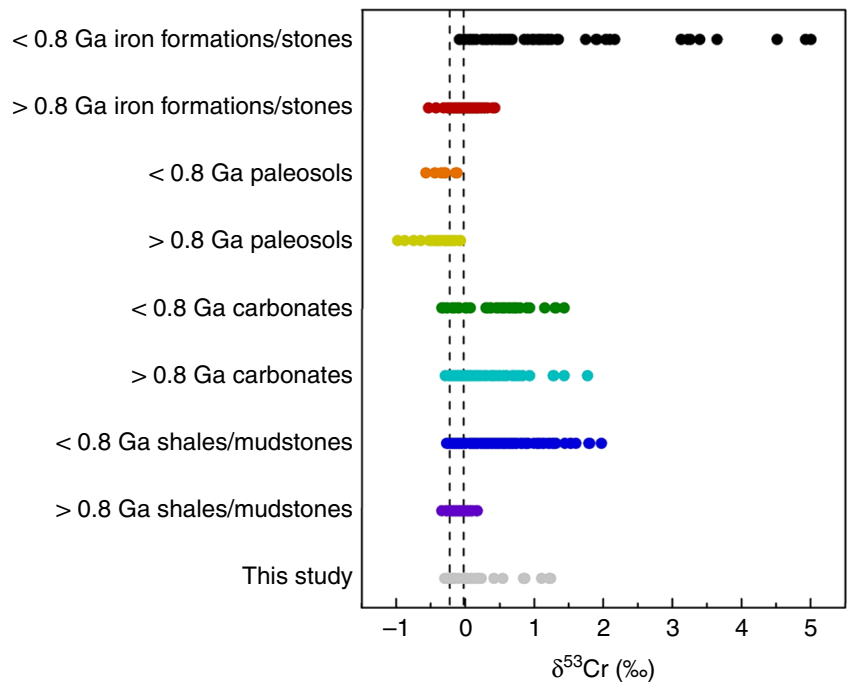

Fig. $6 \mathrm{Cr}$ signatures from this study compared to field data. Redoxindependent $\mathrm{Cr}$ isotope signatures observed in this study compared with previously observed $\delta^{53} \mathrm{Cr}$ ranges from various archives: iron formations/ stones ${ }^{1,3,4,56}$, paleosols ${ }^{3,57}$, carbonates ${ }^{14,56}$, and shales/

mudstones $2,4,5,9,55$. The dashed lines delineate the $\delta^{53} \mathrm{Cr}$ ranges of igneous rocks (mainly basalts and granites) ${ }^{15}$

differently from their corresponding $\mathrm{Fe}(\mathrm{III})$-siderophore complexes $^{27}$. It is important to note that we focus here on dissolution rates rather than dissolution rate constants, which may result in some discrepancies due to siderophore adsorption affinities $^{51}$, which were not the focus of this study.

The stability constants of the metal-ligand complexes can also be correlated with the observed isotopic fractionation factors (Fig. 5) ${ }^{43-45}$. Metal-ligand complexes with the largest stability constants (based on stability constants for the corresponding Fe (III)-ligand) resulted in less positive or more negative fractiona-

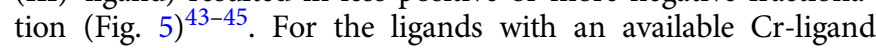
stability constant and dominant species at the experimental conditions, Cr-acetate $(\operatorname{logK}=15)^{43,44}$ and Cr-DFOB $(\operatorname{logK}=33)^{27}$, Cr-acetate does not follow the predicted trend while Cr-DFOB does. A similar trend has been observed with $\mathrm{Fe}$ isotopes during organic acid-promoted dissolution of hornblende ${ }^{52}$. However, in that case the trend encompassed greater fractionation with increasing stability constant, opposite of the observations of this study. If the predominant control is kinetic isotope fractionation, we would expect lighter isotopes (i.e., negative $\Delta^{53} \mathrm{Cr}$ defined as $\left.\Delta^{53} \mathrm{Cr}=\delta^{53} \mathrm{Cr}_{\text {solution }}-\delta^{53} \mathrm{Cr}_{\text {starting solid }}\right)$ to enrich in solution at low dissolved $\mathrm{Cr}$ concentrations and approach the isotopic signature of the starting solid during continued dissolution ${ }^{16}$. In this study, maximum isotopic fractionation was observed relatively soon after the experiment was initiated with isotope values eventually approaching the bulk solid isotope signature at greater dissolved $\mathrm{Cr}$, similar to what has been previously observed with $\mathrm{Fe}$ isotopes during dissolution experiments on $\mathrm{Fe}$ oxides $^{53}$. However, the enrichment of lighter isotopes in the solution during the early stages of dissolution was not evident in our system; instead, positive values for $\Delta^{53} \mathrm{Cr}$ were observed during initial dissolution (Fig. 3). If the $\mathrm{Cr}(\mathrm{III})$-oxygen bond(s) in the ligand is stronger than the $\mathrm{Cr}(\mathrm{III})$-oxygen bonds in the solid, one would expect to see the observed enrichment of heavier isotopes (i.e., positive $\Delta^{53} \mathrm{Cr}$ ) in the dissolved fraction (Fig. 3). However, $\Delta^{53} \mathrm{Cr}$ does not positively correlate to the predicted stability constant of the $\mathrm{Fe}$ (III)-ligand complexes, but instead generally exhibits a negative correlation (Fig. 5) ${ }^{43-45}$. The highly positive $\Delta^{53} \mathrm{Cr}$ values in the treatments with low stability constant ligands (e.g., acetate) may be 


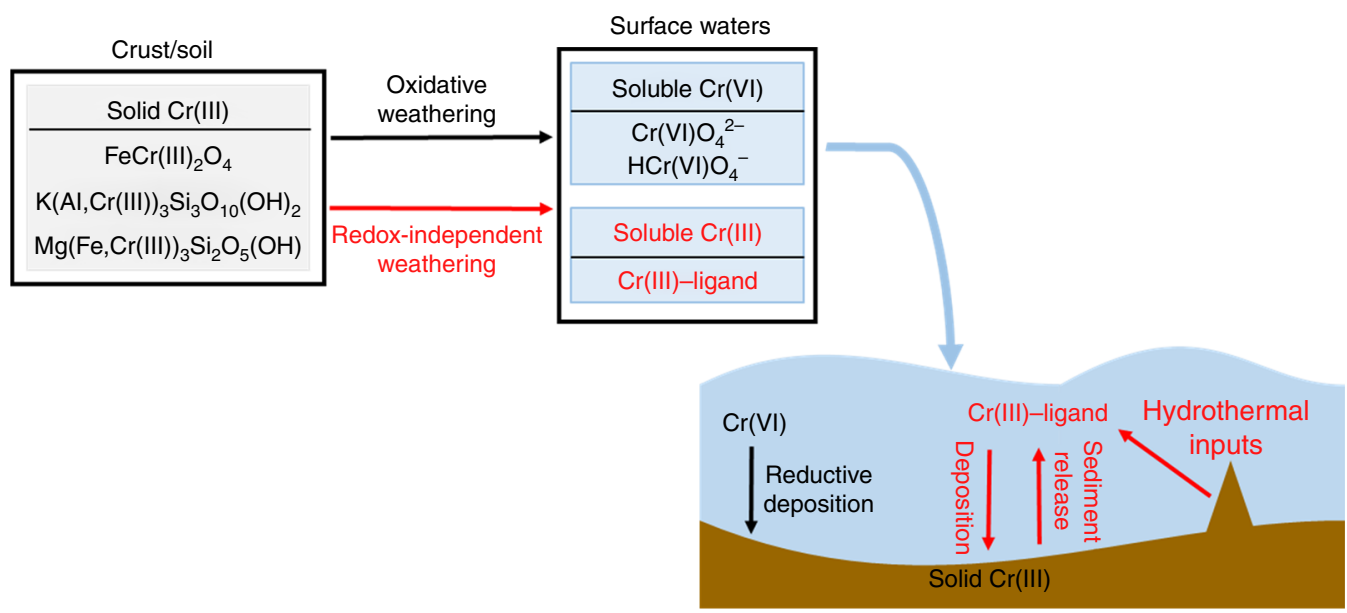

Fig. 7 Suggested updated $\mathrm{Cr}$ cycle. Schematic of $\mathrm{Cr}$ cycle as a paleobarometer for atmospheric oxygen level. Red text and arrows indicate pathways contributing to isotope fractionation that are currently unconstrained, but important in calibration of this system

caused by a fractionation during back reaction of weakly complexed liberated $\mathrm{Cr}(\mathrm{III})$. This process could be insignificant in more strongly bound $\mathrm{Cr}$ (III). Furthermore, if dissolution occurs layer by layer such that ligands complex and dissolve surface $\mathrm{Cr}$ atoms completely before the next layer is exposed and solubilized, a large fractionation may only be observed in the early stages of dissolution ${ }^{16}$. Given that $\mathrm{Cr}(\mathrm{OH})_{3}$ only exhibits a particle size of $<10 \AA$ and is likely a polymer of only a few $\mathrm{CrO}_{6}$ octahedra ${ }^{54}$, rind effects are expected to be minimal for individual particles. However, since heavy aggregation is typically observed for these nanoparticles, rind effects might be more significant at an aggregate level.

Overall, results from this study have important implications for research using the $\mathrm{Cr}$ isotope system as a paleoredox and environmental tracer. Dissolution experiments were conducted at $\mathrm{pH} 7$ in order to isolate the effects of ligand-promoted dissolution on $\mathrm{Cr}(\mathrm{OH})_{3}$ solids. Therefore, despite the lower rates and extents of dissolution relative to proton-promoted dissolution ${ }^{27}$, ligandpromoted dissolution of Cr-containing phases might contribute significantly to $\mathrm{Cr}$ mobilization under nonacidic conditions, such as in the marine environment. For instance, isotopically fractionated $\mathrm{Cr}$ (III) may be leached from dusts or sourced from a benthic flux of organically complexed $\mathrm{Cr}$ (III). Again, the presence of ligand-bound $\mathrm{Cr}$ (III) in the modern oceans supports ligand complexation as an important component of the $\mathrm{Cr} \mathrm{cycle}^{22,25,26}$. Terrestrial waters can also be near neutral or alkaline, suggesting the need to survey for significant ligand complexed $\mathrm{Cr}$ (III) when using $\mathrm{Cr}$ isotopes to monitor $\mathrm{Cr}$ reduction in environmental remediation studies.

The redox-independent $\mathrm{Cr}$ isotope fractionations observed in this study are within the range of values previously reported to reconstruct oxygenation events (Fig. 6) ${ }^{1-5,9,14,15,55-57}$. Therefore, the results from this study bolster the case that the interpretation of the $\mathrm{Cr}$ isotope proxy may need to be revisited in some circumstances to account for redox-independent processes, such as the mobilization of $\mathrm{Cr}$ (III) by organic or inorganic complexing ligands. As previously suggested ${ }^{10,11,14}$, some sedimentary $\mathrm{Cr}$ isotope archives are more likely to be shaped by ligand-bound $\mathrm{Cr}$ and attenuating isotope fractionations associated with organic stabilization. As mentioned above, alkaline systems (e.g., marine systems) may be more likely to express the effects of ligandpromoted solubilization than low $\mathrm{pH}$ systems, given that proton promoted dissolution scales with $\mathrm{pH}$. Marine systems removed from a terrestrial source (e.g., carbonate platforms) might be expected to capture variably fractionated organically or inorganically complexed $\mathrm{Cr}(\mathrm{III})$, such as dissolved $\mathrm{Cr}(\mathrm{III})$-carbonate complexes which have also shown to be significant during ultramafic rock weathering ${ }^{21}$. However, given the high density of organic acids in the weathering realm (see, e.g., ref. ${ }^{38}$ ), soils (and thus paleosols) with evidence for intense weathering may also be susceptible to expression of $\mathrm{Cr}$ (III)-organic isotope fractionations (see, e.g., ref. ${ }^{10}$ ). Therefore, we suggest care should be taken when interpreting negative $\delta^{53} \mathrm{Cr}$ values in paleosol and ancient carbonate rocks as indication of redox cycling of $\mathrm{Cr}^{3,10,58}$.

The common occurrence of organic-bound $\mathrm{Cr}$ (III) in modern environments and the potential for the formation of organic acids throughout the Earth's history indicates that the presented results must be considered when using $\mathrm{Cr}$ isotopes to track the Earth's oxygenation. Further, the presence of both positive and negative $\Delta^{53} \mathrm{Cr}$ values will make it difficult to directly assess the influence of $\mathrm{Cr}(\mathrm{III})-$ ligand isotope effects in deep time studies. However, we emphasize that this does not require abandonment of the basic framework for using $\mathrm{Cr}$ isotopes as a paleoredox proxy, where large $\mathrm{Cr}$ isotope variations in the sedimentary records (e.g., strong deviation from igneous rocks) are a signal for oxidative Cr cycling that can be linked to atmospheric oxygen levels ${ }^{1,3,5}$. The common occurrence of authigenic but isotopically unfractionated $\mathrm{Cr}$ in ancient sedimentary rocks ${ }^{1,4,5}$ implies that $\mathrm{Cr}$ (III) moving through the Earth's surface is not ubiquitously isotopically fractionated by ligand-promoted solubilization, though some small variability is observed in each of these studies. In this light, the possibility of some variable $\mathrm{Cr}$ isotope values should be expected in low oxygen systems (e.g., without $\mathrm{Cr}$ (III) oxidation), and moving forward, the paleoredox $\mathrm{Cr}$ isotope framework must account for this possibility. Despite this added complexity, we suggest that organic complexation is unlikely to lead to a systematic shift in the mean $\delta^{53} \mathrm{Cr}$ value of the mobile $\mathrm{Cr}$ reservoir on a global scale (i.e., the average $\delta^{53} \mathrm{Cr}$ value of dissolved $\mathrm{Cr}$ in freshwater and marine systems), in contrast to extensive $\mathrm{Cr}$ oxidation, which can result in large ${ }^{53} \mathrm{Cr}$-enriched surface reservoirs as observed on the modern and Phanerozoic Earth $^{12,13,59-63}$. Nevertheless, our results imply that some $\mathrm{Cr}$ isotope data from individual formations may lead to ambiguous conclusions about the presence of oxidative $\mathrm{Cr}$ cycling.

Our data provide a step towards accounting for $\mathrm{Cr}$ isotopic variability in the Earth's rock record by pointing toward specific non-redox processes that must be considered in the calibration of the $\mathrm{Cr}$ isotope system as a paleoredox proxy. Our results strongly suggest that fractionations during both redox-dependent and redox-independent $\mathrm{Cr}$ cycling need to be assessed (Fig. 7). In particular, organic ligands can interact with $\mathrm{Cr}$ during both continental weathering and after sediment deposition. However, 
Table 1 Type and structures of siderophores used in this study

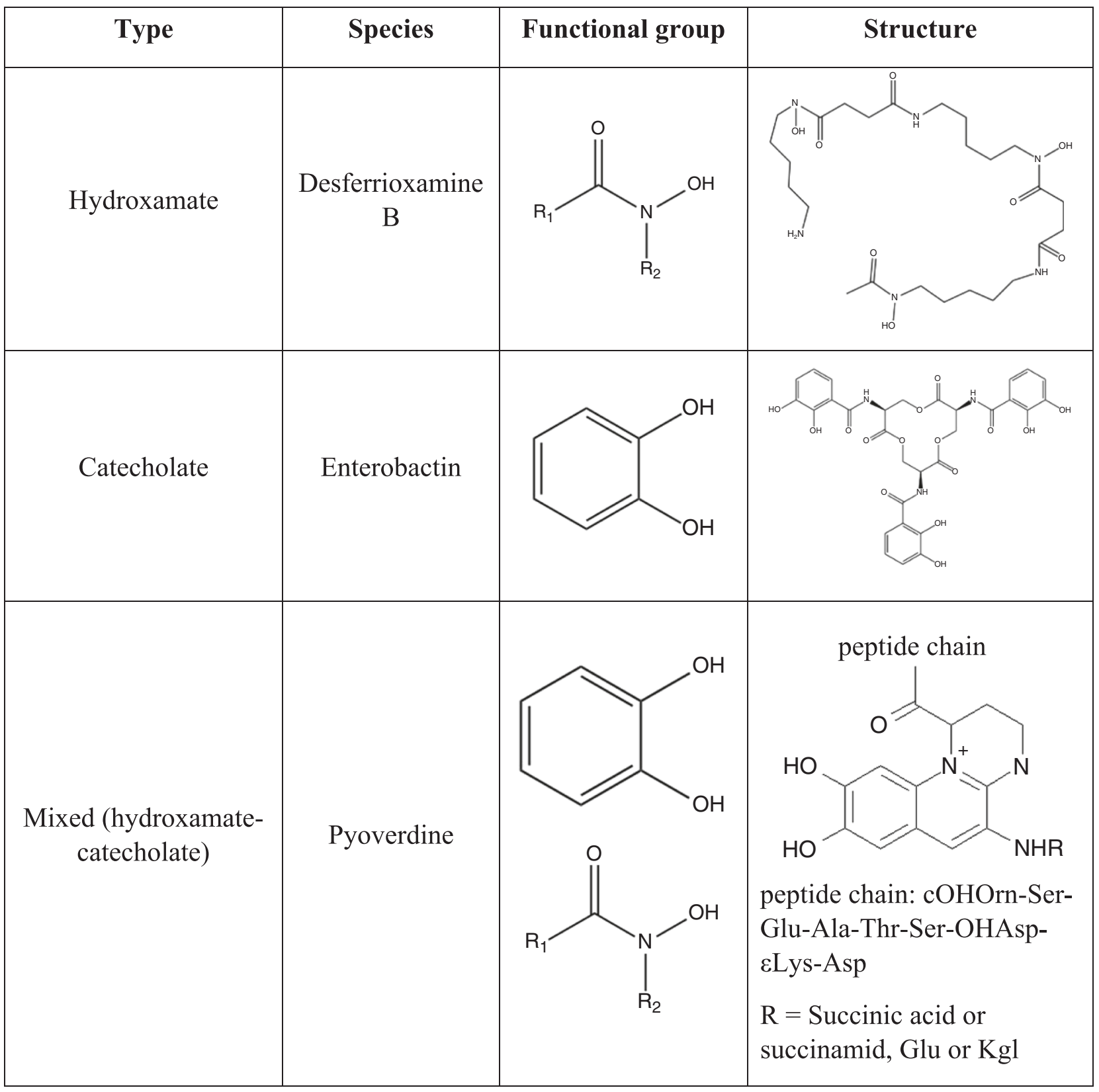

observations from the existing geochemical record and modern natural waters suggest that extensive $\mathrm{Cr}$ redox cycling remains the most effect means for generating significant, large-scale $\mathrm{Cr}$ isotopic variability at Earth's surface.

\section{Methods}

Selection of solid phase and ligands. Amorphous $\mathrm{Cr}$ (III)-(oxy)hydroxide (hereafter referred to as $\mathrm{Cr}(\mathrm{OH})_{3}$ ) was selected as a representative compound for solid-phase $\mathrm{Cr}$ in natural environments as it is a common $\mathrm{Cr}(\mathrm{III})$-containing solid phase, and an endmember in the $\mathrm{Cr}$ (III)-Fe(III)-(oxy)hydroxide solid solution series $^{54}$. A variety of organic ligands and their impacts on $\mathrm{Cr}(\mathrm{OH})_{3}$ dissolution and isotope fractionation were surveyed. Siderophores and organic acids were studied as they are two common classes of metal-complexing organic ligands in the natural environment as previously discussed. Siderophores are generally divided into three primary types based on the characteristic metal binding functional group, including $\alpha$-hydroxycarboxylic acid (hydroxycarboxylate type), catechol (catecholate type), and hydroxamic acid (hydroxamate type $)^{64}$. The most common bacterial and fungal siderophores are catecholates, and hydroxamates, respectively, though other types, including a mixed type, are also quite common and exist with a variety of chemical structures ${ }^{64}$. We chose the following types of siderophores to cover a range of binding types: DFOB (hydroxamate type), enterobactin (catecholate type), and pyoverdine (mixed type) (Table 1). A range of organic acids with different chain lengths and metal binding tendencies were also studied, including oxalate, acetate, succinate, and citrate (Table 2). Cr speciation was monitored throughout the ligand-promoted dissolution experiments to ensure that the effects of redoxindependent processes were specifically isolated.

Synthesis of $\mathrm{Cr}(\mathrm{III})$-(oxy)hydroxide. $\mathrm{Cr}(\mathrm{OH})_{3}$ was synthesized following a previous procedure ${ }^{65}$. Briefly, $\mathrm{Cr}\left(\mathrm{NO}_{3}\right)_{3} \cdot 9 \mathrm{H}_{2} \mathrm{O}$ (ACS grade) was dissolved in deionized water $(18 \mathrm{M} \Omega \mathrm{cm})$ to obtain a total $\mathrm{Cr}$ concentration of $0.1 \mathrm{M}$. The solution was slowly titrated to $\mathrm{pH} 7$ with $1 \mathrm{M} \mathrm{NaOH}$. Precipitates formed from the suspension were aged for $24 \mathrm{~h}$ followed by dialysis to remove remaining electrolytes. The resulting wet pastes were recovered through centrifugation, freeze dried, and finely ground. Portions of the powders were dissolved in nitric acid for $\mathrm{Cr}$ concentration analysis by inductively coupled plasma-mass spectroscopy (ICP-MS; Agilent 
Table 2 Structures of the organic acids used in this study

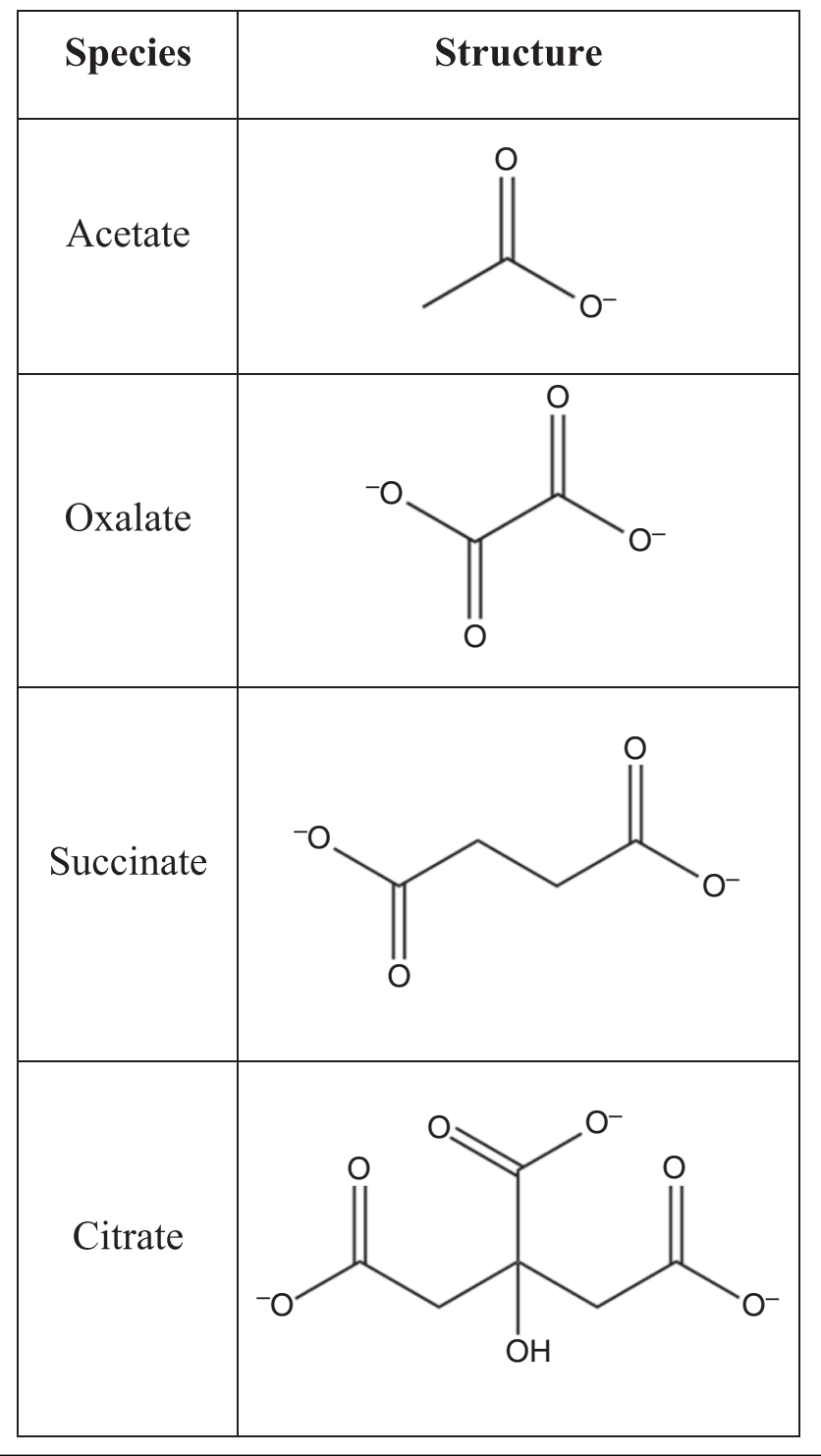

7500a). The specific surface area of the synthesized solid was determined to be $95 \mathrm{~m}^{2} \mathrm{~g}^{-1}$ by Brunauer-Emmett-Teller (BET) gas adsorption analysis using an Autosorb-1-MP surface pore analyzer (Quantachrome Corp.).

Ligand solubilization experiments. The rate and extent of $\mathrm{Cr}(\mathrm{OH})_{3}$ solubilization were investigated in the presence of a single type of siderophore or organic acid, or a combination of siderophore and organic acid. The representative siderophores included DFOB (mesylate salt, Sigma-Aldrich), enterobactin (from Escherichia coli, Sigma-Aldrich), and pyoverdine (from Pseudomonas putida ATCC 12633, EMC Microcollections, Germany). The representative organic acids included acetate, oxalate, succinate, and citrate (all ACS grade from Sigma-Aldrich).

For each ligand solubilization experiment, the $\mathrm{Cr}(\mathrm{OH})_{3}$ solids were suspended in a $0.1 \mathrm{M} \mathrm{NaCl}$ electrolyte solution with $10 \mathrm{mM}$ HEPES buffer (high purity grade, Sigma-Aldrich) at $\mathrm{pH} 7$ and sonicated for $15 \mathrm{~min}$ to disperse the particles. HEPES buffer was previously shown to not influence the rates of siderophore-promoted dissolution of metal hydroxides (see, e.g., refs. ${ }^{27,65,66}$ ). For the treatments containing a siderophore, the siderophore was added to the suspensions to achieve a final concentration of $0.1 \mathrm{mM}$. For the treatments containing an organic acid, the organic acid was added to the suspension to achieve a final concentration of $1 \mathrm{mM}$. For the treatments containing both a siderophore and an organic acid, the organic acid was added $1 \mathrm{~min}$ prior to the siderophore addition in order to account for its potential effect on metal hydroxide dissolution during the initial exposure ${ }^{67}$. Treatments containing organic acids were conducted in triplicate, and treatments containing siderophores were conducted in duplicate. Due to the limitations imposed by the quantities of purchased siderophores, the volumes of each replicate for the siderophores were 50,5 , and $2.4 \mathrm{ml}$ for $\mathrm{DFOB}$, enterobactin, and pyoverdine, respectively. All organic acid treatments were conducted at $50 \mathrm{ml}$ volume. All experiments were conducted at room temperature in the dark using amber bottles, and were constantly agitated on an orbital shaker. A reaction time of $\sim 1$ month was chosen based on previous studies on $\mathrm{Cr}$ isotope exchange rates between aqueous $\mathrm{Cr}(\mathrm{VI})$ and solid $\mathrm{Cr}(\mathrm{III})$ oxyhydroxide at $\mathrm{pH} 7^{19}$ and between various $\mathrm{Cr}-\mathrm{Cl}$ species at low $\mathrm{pH}^{7}$, both suggesting significant to complete isotope exchange may occur within a few months.

Throughout the experiments, $100 \mu \mathrm{l}$ of filtered $(0.2 \mu \mathrm{m}$, cellulose acetete) aliquots of each sample were collected at certain time points and analyzed for total dissolved $\mathrm{Cr}$ concentration by ICP-MS. $\mathrm{Cr}(\mathrm{VI})$ concentrations in the filtrates were analyzed using the diphenylcarbazide assay ${ }^{68}$ on an UV-vis spectrophotometer (Cary 60, Agilent) and were below the detection limit $(0.2 \mu \mathrm{M})$ for all treatments. Thus, the total dissolved $\mathrm{Cr}$ concentration in the filtrate was considered to be $\mathrm{Cr}$ (III). The $\mathrm{pH}$ values of the reaction suspensions stayed at $7.0 \pm 0.1$ throughout the entire experiment for all treatments. No microbial growth was observed for the duration of the experiment. $\mathrm{Cr}$ release rates were determined by fitting a regression line through the linear portion of the dissolution profile for each condition, and were normalized to BET surface area for consistency of comparison with previous studies on ligand-promoted dissolution of $\mathrm{Cr}(\mathrm{OH})_{3}{ }^{27}$.

$\mathrm{Cr}$ isotope analysis. At various time points along the dissolution profile, an entire sample bottle was sacrificed for $\mathrm{Cr}$ isotope analysis, thus reflecting the cumulative isotope signature at that time point. The ${ }^{50} \mathrm{Cr}-{ }^{54} \mathrm{Cr}$ double spike method was used to correct for fractionation during sample purification and isotope measurement ${ }^{15,69}$. The double spike solution with known ${ }^{50} \mathrm{Cr} /{ }^{54} \mathrm{Cr}$ ratio $(\sim 1)$ was added as early as possible in the sample preparation process and was added in the same valence(s) as the $\mathrm{Cr}$ in the sample (i.e., $\mathrm{Cr}(\mathrm{III})$ ). Proper amount of spike was added to the filtered samples to ensure an optimum spike/sample ratio of ${ }^{54} \mathrm{Cr}_{\text {spike }} /$ ${ }^{52} \mathrm{Cr}_{\text {sample }} \sim 0.5$. Cr was purified from matrix ions using a cation exchange resin method modified from Bonnand et al. ${ }^{70}$. Briefly, the sample-spike mixtures were gently evaporated to dryness and refluxed with $6 \mathrm{~N} \mathrm{HCl}$ to allow full isotopic equilibrium between spike and sample. Samples were then dissolved in $0.5 \mathrm{~N} \mathrm{HCl}$ and loaded onto Bio-Rad AG50W-X8 (100-200 mesh) cation exchange resin. Cr was eluted from the resin after loading and collected for isotope analysis. Purified $\mathrm{Cr}$ samples were dissolved in $0.7 \mathrm{~N} \mathrm{HNO}_{3}$ and measured for $\mathrm{Cr}$ isotopic compositions on a NeptunePlus multicollector ICP-MS. Ti, V, and Fe interferences were monitored and corrected, with corrections typically $<0.1 \%$. A concentration matched unprocessed SRM 979 standard was analyzed before and after every sample to monitor instrument drift. Sample values were normalized to the average values of the bracketing standards. Based on standards and duplicate preparation and analysis of various types of real samples, our analytical precision was about $\pm 0.08 \%$ o (95\% confidence level) using $200-1000 \mathrm{ng} \mathrm{Cr}$. The starting $\mathrm{Cr}(\mathrm{OH})_{3}$ solid was dissolved by $0.7 \mathrm{~N} \mathrm{HNO}_{3}$ and analyzed for $\mathrm{Cr}$ isotopic composition as described above and was $-0.08 \pm 0.04 \%$. The total procedural blank ranged from 0.2 to $1 \mathrm{ng}$, which is negligible compared to the sample $\mathrm{Cr}$ amount; therefore, blank correction was not performed.

Data availability. Data sets generated during and/or analyzed during the current study are available from the corresponding author on reasonable request.

Received: 11 April 2017 Accepted: 9 October 2017 Published online: 17 November 2017

\section{References}

1. Frei, R., Gaucher, C., Poulton, S. W. \& Canfield, D. E. Fluctuations in precambrian atmospheric oxygenation recorded by chromium isotopes. Nature 461, 250-253 (2009).

2. Frei, R., Gaucher, C., Stolper, D. \& Canfield, D. E. Fluctuations in late neoproterozoic atmospheric oxidation- $\mathrm{Cr}$ isotope chemostratigraphy and iron speciation of the late Ediacaran lower Arroyo del Soldado Group (Uruguay). Gondwana Res. 23, 797-811 (2013).

3. Crowe, S. A. et al. Atmospheric oxygenation three billion years ago. Nature 501, 535 (2013).

4. Planavsky, N. J. et al. Low Mid-Proterozoic atmospheric oxygen levels and the delayed rise of animals. Science 346, 635-638 (2014).

5. Cole, D. B. et al. A shale-hosted $\mathrm{Cr}$ isotope record of low atmospheric oxygen during the Proterozoic. Geology 44, 555-558 (2016).

6. Ellis, A. S., Johnson, T. M. \& Bullen, T. D. Using chromium stable isotope ratios to quantify $\mathrm{Cr}(\mathrm{VI})$ reduction: lack of sorption effects. Environ. Sci. Technol. $\mathbf{3 8}$ 3604-3607 (2004).

7. Larsen, K. K., Wielandt, D., Schiller, M. \& Bizzarro, M. Chromatographic speciation of $\mathrm{Cr}$ (III)-species, inter-species equilibrium isotope fractionation and improved chemical purification strategies for high-precision isotope analysis. J. Chromatogr. A 1443, 162-174 (2016). 
8. Qin, L. \& Wang, X. Chromium isotope geochemistry. Rev. Mineral. Geochem. 82, 379-414 (2017).

9. Gueguen, B. et al. The chromium isotope composition of reducing and oxic marine sediments. Geochim. Cosmochim. Acta 184, 1-19 (2016).

10. Babechuk, M. G., Kleinhanns, I. C. \& Schoenberg, R. Chromium geochemistry of the ca. $1.85 \mathrm{Ga}$ flin flon paleosol. Geobiology 15, 30-50 (2017).

11. Konhauser, K. O. et al. Aerobic bacterial pyrite oxidation and acid rock drainage during the great oxidation event. Nature 478, 369-373 (2011).

12. Paulukat, C., Gilleaudeau, G. J., Chernyavskiy, P. \& Frei, R. The Cr-isotope signature of surface seawater-a global perspective. Chem. Geol. 444, 101-109 (2016).

13. Scheiderich, K., Amini, M., Holmden, C. \& Francois, R. Global variability of chromium isotopes in seawater demonstrated by Pacific, Atlantic, and Arctic ocean samples. Earth Planet Sci. Lett. 423, 87-97 (2015).

14. Holmden, C., Jacobson, A. D., Sageman, B. B. \& Hurtgen, M. T. Response of the $\mathrm{Cr}$ isotope proxy to cretaceous ocean anoxic event 2 in a pelagic carbonate succession from the western interior seaway. Geochim. Cosmochim. Acta 186, 277-295 (2016).

15. Schoenberg, R., Zink, S., Staubwasser, M. \& von Blanckenburg, F. The stable Cr isotope inventory of solid Earth reservoirs determined by double spike MCICP-MS. Chem. Geol. 249, 294-306 (2008).

16. Johnson, T. M. \& Bullen, T. D. in Geochemistry of Non-Traditional Stable Isotopes Vol. 55 Reviews in Mineralogy \& Geochemistry (eds C. M. Johnson et al.) 289-317 (Mineralogical Society of America, Washington DC, 2004).

17. Xia, J. et al. Chromium isotope heterogeneity in the mantle. Earth Planet Sci. Lett. 464, 103-115 (2017).

18. Altman, C. \& King, E. L. The mechanism of the exchange of chromium(III) and chromium(VI) in acidic solution1-3. J. Am. Chem. Soc. 83, 2825-2830 (1961).

19. Wang, X. L., Johnson, T. M. \& Ellis, A. S. Equilibrium isotopic fractionation and isotopic exchange kinetics between $\mathrm{Cr}(\mathrm{III})$ and $\mathrm{Cr}(\mathrm{VI})$. Geochim. Cosmochim. Acta 153, 72-90 (2015).

20. Schauble, E., Rossman, G. R. \& Taylor, H. P. Theoretical estimates of equilibrium chromium-isotope fractionations. Chem. Geol. 205, 99-114 (2004).

21. McClain, C. N. \& Maher, K. Chromium fluxes and speciation in ultramafic catchments and global rivers. Chem. Geol. 426, 135-157 (2016).

22. Nakayama, E., Tokoro, H., Kuwamoto, T. \& Fujinaga, T. Dissolved state of chromium in seawater. Nature 290, 768-770 (1981).

23. Kaczynski, S. E. \& Kieber, R. J. Hydrophobic C18 bound organic complexes of chromium and their potential impact on the geochemistry of $\mathrm{Cr}$ in natural waters. Environ. Sci. Technol. 28, 799-804 (1994).

24. Icopini, G. A. \& Long, D. T. Speciation of aqueous chromium by use of solid-phase extractions in the field. Environ. Sci. Technol. 36, 2994-2999 (2002).

25. Sander, S. \& Koschinsky, A. Onboard-ship redox speciation of chromium in diffuse hydrothermal fluids from the north Fiji basin. Mar. Chem. 71, 83-102 (2000).

26. Sander, S. G. \& Koschinsky, A. Metal flux from hydrothermal vents increased by organic complexation. Nat. Geosci. 4, 145-150 (2011)

27. Duckworth, O. W., Akafia, M. M., Andrews, M. Y. \& Bargar, J. R. Siderophorepromoted dissolution of chromium from hydroxide minerals. Environ. Sci. Process Impacts 16, 1348-1359 (2014).

28. Carbonaro, R. F., Gray, B. N., Whitehead, C. F. \& Stone, A. T. Carboxylatecontaining chelating agent interactions with amorphous chromium hydroxide: adsorption and dissolution. Geochim. Cosmochim. Acta 72, 3241-3257 (2008)

29. Fan, T. W. M., Lane, A. N., Pedler, J., Crowley, D. \& Higashi, R. M. Comprehensive analysis of organic ligands in whole root exudates using nuclear magnetic resonance and gas chromatography mass spectrometry. Anal. Biochem. 251, 57-68 (1997).

30. Neilands, J. B. Siderophores: structure and function of microbial iron transport compounds. J. Biol. Chem. 270, 26723-26726 (1995).

31. Duckworth, O. W. et al. The exceptionally stable cobalt(III)-desferrioxamine B complex. Mar. Chem. 113, 114-122 (2009).

32. Pohlman, A. A. \& McColl, J. G. Kinetics of metal dissolution from forest soils by soluble organic acids. J. Environ. Qual. 15, 86-92 (1986).

33. James, B. R. \& Bartlett, R. J. Behavior of chromium in soils. 5. Fate of organiccaly complexed Cr(III) added to soil. J. Environ. Qual. 12, 169-172 (1983).

34. Srivastava, S., Prakash, S. \& Srivastava, M. M. Chromium mobilization and plant availability-the impact of organic complexing ligands. Plant Soil 212, 203-208 (1999)

35. Gustafsson, J. P. et al. Chromium(III) complexation to natural organic matter: mechanisms and modeling. Environ. Sci. Technol. 48, 1753-1761 (2014).

36. Dalai, P., Kaddour, H. \& Sahai, N. Incubating life: prebiotic sources of organics for the origin of life. Elements 12, 401-406 (2016).
37. Boenigk, J., Wodniok, S. \& Glücksman, E. Biodiversity and Earth History (Springer, Heidelberg, 2015).

38. Neaman, A., Chorover, J. \& Brantley, S. L. Implications of the evolution of organic acid moieties for basalt weathering over geological time. Am. J. Sci. 305, 147-185 (2005).

39. Stumm, W. Chemistry of the Solid-Water Interface: Processes at the MineralWater and Particle-Water Interface in Natural Systems (Wiley-Interscience, New York,1992).

40. Hernlem, B. J., Vane, L. M. \& Sayles, G. D. Stability constants for complexes of the siderophore desferrioxamine B with selected heavy metal cations. Inorganica. Chim. Acta 244, 179-184 (1996).

41. Shannon, R. D. Revised effective ionic-radii and systematic studies of interactomic distances in halides and chalcogenides. Acta Cryst. A 32, 751-767 (1976).

42. Harrington, J. M. et al. Trace metal complexation by the triscatecholate siderophore protochelin: structure and stability. Biometals 25, 393-412 (2012).

43. Gustafsson, J. P. Visual MINTEQ v. 3.1 (Stockholm, 2016).

44. Martell, A. E. \& Smith, R. M. NIST Critically Selected Stability Constants of Metal Complexes Database. (NIST: Gaithersburg, 2004).

45. Boukhalfa, H. \& Crumbliss, A. L. Chemical aspects of siderophore mediated iron transport. Biometals 15, 325-339 (2002).

46. Johnson, S. E. \& Loeppert, R. H. Role of organic acids in phosphate mobilization from iron oxide. Soil Sci. Soc. Am. J. 70, 222-234 (2006).

47. Cornell, R. M. \& Schindler, P. W. Infrared study of the adsorption of hydroxycarboxylic acids on alpha- $\mathrm{FeOOH}$ and amorphous $\mathrm{Fe}(\mathrm{III})$ hydroxide. Colloid Polym. Sci. 258, 1171-1175 (1980).

48. Duckworth, O. W. \& Martin, S. T. Surface complexation and dissolution of hematite by C-1-C-6 dicarboxylic acids at $\mathrm{pH}=5.0$. Geochim. Cosmochim. Acta 65, 4289-4301 (2001).

49. Martin, S. in Environmental Catalysis (ed. V. H. Grassian) Ch. 3 (CRC, Boca Raton, 2005).

50. Akafia, M. M., Harrington, J. M., Bargar, J. R. \& Duckworth, O. W. Metal oxyhydroxide dissolution as promoted by structurally diverse siderophores and oxalate. Geochim. Cosmochim. Acta 141, 258-269 (2014).

51. Wang, Z. M., Schenkeveld, W. D. C., Kraemer, S. M. \& Giammar, D. E. Synergistic effect of reductive and ligand-promoted dissolution of Goethite. Environ. Sci. Technol. 49, 7236-7244 (2015).

52. Brantley, S. L. et al. Fe isotopic fractionation during mineral dissolution with and without bacteria. Geochim. Cosmochim. Acta 68, 3189-3204 (2004).

53. Wiederhold, J. G. et al. Iron isotope fractionation during proton-promoted, ligand-controlled, and reductive dissolution of goethite. Environ. Sci. Technol. 40, 3787-3793 (2006).

54. Tang, Y. Z. et al. Structural properties of the $\mathrm{Cr}(\mathrm{III})-\mathrm{Fe}(\mathrm{III})$ (oxy)hydroxide compositional series: Insights for a nanomaterial "solid solution". Chem. Mat. 22, 3589-3598 (2010).

55. Reinhard, C. T. et al. The isotopic composition of authigenic chromium in anoxic marine sediments: a case study from the Cariaco basin. Earth Planet Sci. Lett. 407, 9-18 (2014).

56. Frei, R., Gaucher, C., Dossing, L. N. \& Sial, A. N. Chromium isotopes in carbonates-a tracer for climate change and for reconstructing the redox state of ancient seawater. Earth Planet Sci. Lett. 312, 114-125 (2011).

57. Berger, A. \& Frei, R. The fate of chromium during tropical weathering: a laterite profile from Central Madagascar. Geoderma 213, 521-532 (2014).

58. Frei, R. \& Polat, A. Chromium isotope fractionation during oxidative weathering-implications from the study of a paleoproterozoic (ca. 1.9Ga) paleosol, Schreiber Beach, Ontario, Canada. Precambrian Res. 224, 434-453 (2013).

59. Novak, M. et al. Common occurrence of a positive delta53Cr shift in Central European waters contaminated by geogenic/industrial chromium relative to source values. Environ. Sci. Technol. 48, 6089-6096 (2014).

60. Izbicki, J. A., Bullen, T. D., Martin, P. \& Schroth, B. Delta chromium-53/52 isotopic composition of native and contaminated groundwater, Mojave desert, USA. Appl. Geochem. 27, 841-853 (2012).

61. Berna, E. C., Johnson, T. M., Makdisi, R. S. \& Basui, A. Cr stable isotopes as indicators of $\mathrm{Cr}(\mathrm{vi})$ reduction in groundwater: a detailed time-series study of a point-source plume. Environ. Sci. Technol. 44, 1043-1048 (2010).

62. D’Arcy, J., Babechuk, M. G., Dossing, L. N., Gaucher, C. \& Frei, R. Processes controlling the chromium isotopic composition of river water: constraints from basaltic river catchments. Geochim. Cosmochim. Acta 186, 296-315 (2016).

63. Wu, W., Wang, X., Reinhard, C. T. \& Planavsky, N. J. Chromium isotope systematics in the Connecticut river. Chem. Geol. 456, 98-111 (2017).

64. Ahmed, E. \& Holmstrom, S. J. M. Siderophores in environmental research: roles and applications. Microbial. Biotechnol. 7, 196-208 (2014). 
65. Saad, E. M. et al. Siderophore and organic acid promoted dissolution and transformation of $\mathrm{Cr}(\mathrm{III})-\mathrm{Fe}(\mathrm{III})-(\mathrm{oxy})$ hydroxides. Environ. Sci. Technol. 51, 3223-3232 (2017)

66. Bi, Y. Q., Hesterberg, D. L. \& Duckworth, O. W. Siderophore-promoted dissolution of cobalt from hydroxide minerals. Geochim. Cosmochim. Acta 74, 2915-2925 (2010).

67. Reichard, P. U., Kretzschmar, R. \& Kraemer, S. M. Dissolution mechanisms of goethite in the presence of siderophores and organic acids. Geochim. Cosmochim. Acta 71, 5635-5650 (2007).

68. Bartlett, R. \& James, B. Behavior of chromium in soils. 3. Oxidation. J. Environ. Qual. 8, 31-35 (1979).

69. Ellis, A. S., Johnson, T. M. \& Bullen, T. D. Chromium isotopes and the fate of hexavalent chromium in the environment. Science 295, 2060-2062 (2002).

70. Bonnand, P., Parkinson, I. J., James, R. H., Karjalainen, A. M. \& Fehr, M. A. Accurate and precise determination of stable $\mathrm{Cr}$ isotope compositions in carbonates by double spike MC-ICP-MS. J. Anal. At. Spectrom. 26, 528-535 (2011).

\section{Acknowledgements}

This project is support by NASA Astrobiology Institute under Cooperative Agreement No. NNA15BB03A, NASA Exobiology grant NNX16AL06G, and Agouron Institute Postdoctoral Fellowship (to X.W.). We greatly appreciate the comments from the reviewers, which significantly strengthened the manuscript.

\section{Author contributions}

Y.T., N.J.P. and C.T.R. planned the research, E.M.S. conducted the batch experiments and analyzed the data, X.W. performed the isotope analysis. E.M.S. wrote the manuscript, and all authors commented on the manuscript.

\section{Additional information}

Supplementary Information accompanies this paper at doi:10.1038/s41467-017-01694-y.

Competing interests: The authors declare no competing financial interests.

Reprints and permission information is available online at http://npg.nature.com/ reprintsandpermissions/

Publisher's note: Springer Nature remains neutral with regard to jurisdictional claims in published maps and institutional affiliations.

(c) (i) Open Access This article is licensed under a Creative Commons Attribution 4.0 International License, which permits use, sharing, adaptation, distribution and reproduction in any medium or format, as long as you give appropriate credit to the original author(s) and the source, provide a link to the Creative Commons license, and indicate if changes were made. The images or other third party material in this article are included in the article's Creative Commons license, unless indicated otherwise in a credit line to the material. If material is not included in the article's Creative Commons license and your intended use is not permitted by statutory regulation or exceeds the permitted use, you will need to obtain permission directly from the copyright holder. To view a copy of this license, visit http://creativecommons.org/ licenses/by/4.0/.

(C) The Author(s) 2017 